\title{
Solar retinopathy from sun-gazing under the influence of LSD
}

\author{
H. SGHATZ* AND F. MENDELBLATT $\dagger$ \\ From the Wilmer Institute, Johns Hopkins Hospital*, Baltimore, and 534 Sixth Avenue $\dagger$, South St. \\ Petersburg, Florida 3370 I, U.S.A.
}

Solar retinopathy is a condition that can result from focusing the eye(s) on the sun, and usually follows the independent viewing of a solar eclipse. It has also been reported after direct sun-gazing, in anti-aircraft lookouts (Flynn, I942; Cordes, 1944, 1948), in military recruits hoping to obtain discharge from service (Ewald and Ritchey, 1970), in hospitalized schizophrenic patients (Anaclerio and Wicker, 1970), in individuals observing the sun as a religious ritual (Agarwal and Malik, I959), in sunbathers (MacFaul, I969; Ridgway, 1967), in patients trying to blind themselves (Eigner, 1966), and recently in patients under the influence of LSD (Ewald and Ritchey, 1970; Ewald, 1971). Cases have also been reported following indirect or reflected sunlight injury, from water or desert sand (Rosen, I948; Irvine, 1945), and in patients undergoing "prolonged and unprotected exposure to the infra-red rays of the solar spectrum in the tropics" (Smith, 1944). It has recently been suggested (Manchester and Manchester, 1972) that the temporary blindness of Saul of Tarsus may have been the result of solar retinopathy.

After a sun-gazing episode, patients complain of some or all of the following symptoms: decreased or foggy vision, central scotoma, metamorphopsia, chromatopsia, and headache.

The initial visual acuity after solar injury is usually $20 / 40$ to $20 / 60$, but may range from $20 / 20$ to counting fingers. After approximately 6 months, the visual acuity is usually in the range of $20 / 20$ to $20 / 40$, although it has been reported as low as 20/400 (Rosen, 1948). Patients who regain 20/20 vision often complain of permanent minute central scotomas (Flynn, I96oa; MacFaul, i969).

The initial ophthalmoscopic picture varies - from no change to marked macular oedema. Within 1 to 2 weeks, pigmentation in a mottled pattern replaces the oedema. Later, a hole in the fovea develops. Whether this is a true through-and-through hole in the retina is not known because no histopathological specimens have been available for study.

This paper describes two young patients who ingested lysergic acid diethylamide (LSD) and, while under its effect, gazed at the sun. Bilateral solar retinopathy resulted in each patient.

\section{Case reports}

Case I, a 24-year-old Caucasian male, was examined one day after sun gazing. He reported being attracted by the glow of the setting sun while under the influence of LSD. He stated that the sun had the significance of God to him, and that a religious experience occurred during this episode. He immediately noted blurred vision, spots, difficulty in reading, and the need to look to the side of any object to see it clearly. He realized that eye damage had occurred, and he was examined the following morning. 
At the time of examination, the visual acuity was 20/30 in each eye. Small central scotomas were recorded. Each macula showed oedema radiating from the fovea. The remainder of the anterior and posterior segment examination of each eye was normal. The patient was diagnosed as having bilateral solar retinopathy and was treated with prednisone $15 \mathrm{mg}$. four times a day.

The following day the visual acuity was $20 / 40+$ in each eye, and the maculae showed slightly more oedema; 2 days later, the acuity was 20/25 in the right eye and 20/20 in the left, and the maculae showed less oedema. The systemic steroids were reduced, and 5 days later (9 days after the first examination), the visual acuity was the same and the oedema had resolved. Early pigmentation was present at each macula, extending radially from the fovea. Systemic steroids were discontinued.

At the last examination, 4 months after the injury, the maculae showed pit-like foveal depressions or holes, and fine pigmentation extended radially, occupying the areas where the oedema was initially noted (Fig. I). The visual acuity was $20 / 20$ in each eye, but the patient was constantly aware of small scotomas. He still looks to the side of each letter to read it more accurately, and still sees spots before each eye.

Since his first examination, he has been hospitalized on the psychiatric service for LSD overdose on two occasions. His psychiatric diagnosis is paranoid schizophrenia. General physical findings are all within normal limits, and there are no abnormalities in the peripheral vascular system. There is no family history of eye disease or macular degeneration. An eye examination before this solar injury showed that his eyes were normal without macular disease. The cyclogyl refraction was: right eye 20/20, with + I D sph., $-0.5 \mathrm{D}$ cyl., axis $90^{\circ}$, and left eye 20/20 with $+\mathrm{I} \cdot 5 \mathrm{D}$. sph., -0.5 D. cyl., axis $90^{\circ}$. Fluorescein fundus angiography was refused.

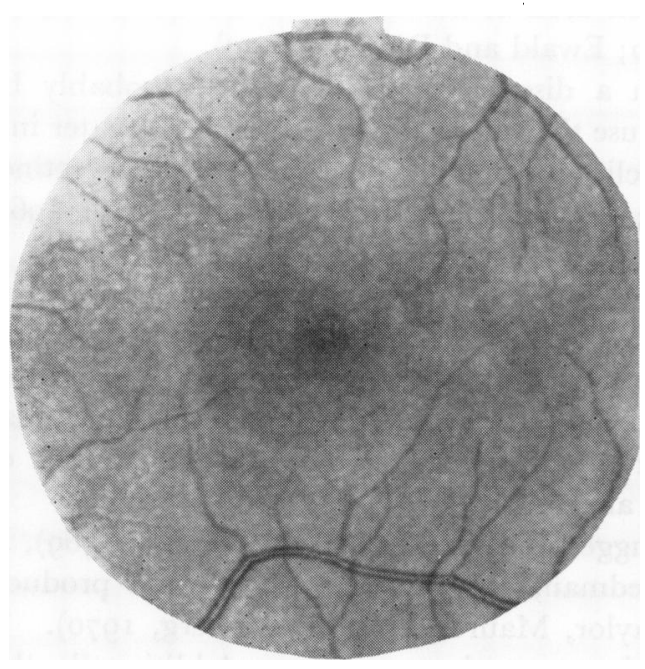

FIG. I Case I. Appearance of macula 4 months after sun-gazing episode

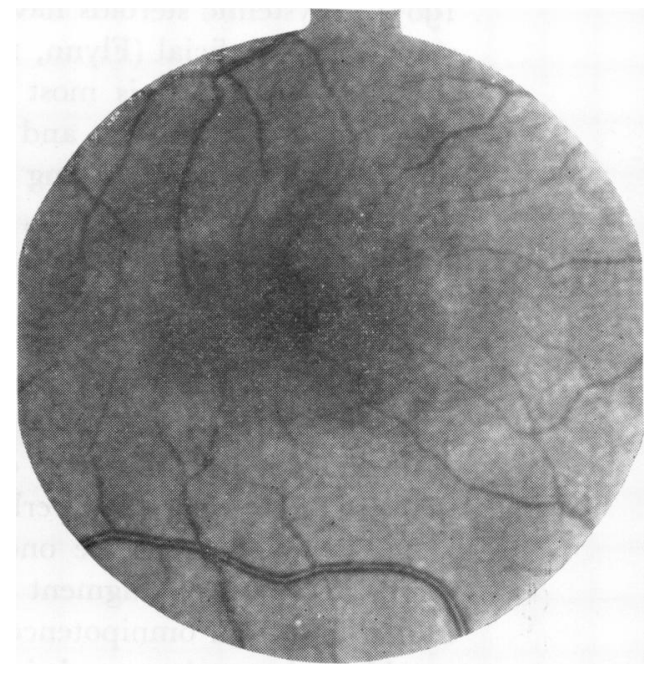

FIG. 2 Case 2. Appearance of macula 2 months after sun-gazing episode

Case 2, a r5-year-old Caucasian female, heard a lecture at her public high school warning of the harmful effects of the illicit use of drugs. The lecturer told the audience that one could sustain a retinal burn with loss of vision if one gazed at the sun while under the influence of hallucinogenic drugs. The patient thought that "it would be a neat thing to burn out my retinas". She then proceeded to take LSD, having taken it "a few times before", and stared at the sun for an unknown length of time. A feeling of omnipotence was experienced and she was not concerned about permanent damage to her vision.

For the first week after the sun-gazing episode, she reported inability to read newspaper print and written material on the blackboard at school. Her sight gradually improved, and when she was 
first seen, 2 weeks after the episode, for headache, the visual acuity was $20 / 25$ with slight eccentric fixation in both eyes. Central visual field and Amsler grid showed a very small central scotoma in each eye.

The foveal reflex was absent and both maculae showed mild pigment stippling. During the next 2 months the sight in each eye improved to 20/20 minus with slight eccentric fixation. The central scotomas became minute, and each macula developed a ring of stippled pigment around a small red depressed area in the fovea, which under slit-lamp examination looked like a hole (Fig. 2). The patient was emmetropic. Otherwise the eyes were normal. Fluorescein fundus angiography was normal.

The general physical examination was normal, and there was no evidence of peripheral vascular disease. Psychiatric consultation revealed that the patient had a hysterical personality. The family history was negative for macular disease.

\section{Discussion}

The lesion of solar retinopathy results from the thermal effect of the long visible and infrared rays of the sun (Cogan, I963; MacFaul, I969; Flynn, 1942). Less than a minute of direct focus of the sun's rays on the macula is all that is necessary to cause the lesion (Verhoeff, Bell, and Walker, I9I6). Longer exposure increases the severity (Irvine, I945). No devices - such as sunglasses, filters, dark photographic films, etc.- that can adequately protect the retina from damage by focused sunlight are generally or easily available, although a simple device for viewing an eclipse indirectly has been described (Cogan, I963). Systemic steroids have been used in the treatment of solar retinopathy and these seem to be beneficial (Flynn, I96ob; Ewald and Ritchey, 1970).

Solar retinopathy is most often a disease of young people, probably because their ocular media are clearer, and because the sun seems to generate a greater interest among the young, especially during an eclipse. A higher incidence of solar retinopathy is reported among males (Cogan, I963; Flynn, I960a,b; Gupta and Mehra, I964; MacFaul, I969; Das, Nirankari, and Chaddah, I956).

An association can be drawn between LSD and sun-gazing in our two patients. LSD produces a heightened degree of awareness of visual imagery (Horowitz, I969; Smith, 1969). As a result, LSD users tend to be attracted to bright and colourful objects, with a sense of added appreciation of what is perceived. It is known that LSD dilates the pupil (Freedman, 1969), and this can result in a higher concentration of light energy being delivered to the macula (Verhoeff and others, igi6).

LSD can also increase one's suggestibility (Glew, I966: Smith, I969), impair good sense, disorganize judgment (Freedman, I968; Smith, I969), and produce feelings of immortality and omnipotence (Taylor, Maurer, and Tinklenberg, 1970). These effects would tend to reduce one's inhibitions towards sun-gazing. Additionally, the drug shows its most harmful effects on unstable, emotionally disturbed people. The psychiatric findings in our patients indicate that they were highly susceptible to the dangers of LSD.

Louria (I968) wrote, " The dramatic and often tragic untoward reactions to LSD are well known. These include acute psychosis, acting out of sociopathic or homosexual impulses, inadvertent or intentional suicidal attempts, convulsions, uncontrolled aggression (including attempted homicide), and overwhelming, ego-shattering panic reactions." Our patients demonstrate that sun-gazing is an additional danger, of which ophthalmologists must be aware.

\section{Summary}

Solar retinopathy is a well-known condition that can result from the thermal effects of direct 
or indirect rays of the sun focused on the retina. Two cases of solar retinopathy are reported in young patients who gazed at the sun under the influence of LSD.

The possible presence of solar retinopathy should be considered in patients, especially young people, who present one or more of the following symptoms: decreased visual acuity, central scotoma, and chromatopsia, especially when macular oedema, macular pigmentation, and/or a small, red, depressed lesion of the fovea are seen with the ophthalmoscope.

We thank Dr. Craig Willoth, Captain, USAF, for referring the second patient.

\section{References}

AgARWAL, L. P., and MAlik, s. R. K. (1959) Brit. F. Ophthal., 43, 366

ANAGLerio, A. M., and Wicker, H. s. (1970) Amer. F. Ophthal., 69, 731

GoGan, D. G. (1963) Arch. Ophthal. (Chicago), 69, 69o

CORDES, F. c. (1944) Amer. F. Ophthal., 27, 803

$$
\text { (1984) Ibid., 31, 10 I }
$$

DAS, T., NIRANKARI, M. s., and CHADDAH, M. R. (1956) Ibid., 4I, I048

EIGNER, E. H. (1966) Ibid., 61, 1546

EWALD, R. A. (197I) Ann. Ophthal., 3, I5 and RITCHEY, C. L. (1970) Ibid., 70, 49I

flynN, J. A. (1942) Med. F. Aust., 2, 400

(1960a) Trans. ophthal. Soc. Aust., 20, 90 (196ob) Med. F. Aust., 1, 85

freedman, D. X. (1968) Arch. gen. Psychiat., 18, 330 (1969) Ann. Rev. Med., 20, 409

GLEW, D. H., Jr. (1966) Milit. Med., r31, I 340

Gupta, R. B. L., and mehra, s. K. (Ig64) 7 . Indian med. Ass., 43, 268

HOROWItz, M. J. (1969) Amer. F. Psychiat., 126, 565

IRVINE, s. R. (1945) Amer. F. Ophthal., 28, I 158

LOURIA, D. B. (1968) New. Engl. F. Med., 278, 435

MAGFAUl, P. A. (1969) Brit. 7. Ophthal., 53, 534

MANGheSter, P. T., and manchester, P. T., Jr. (1972) Arch. Ophthal. (Chicago), 88, 316

RIDGWAY, A. E. A. (1967) Brit. med. F., 3, 212

ROSEN, E. (1948) Brit. F. Ophthal., 32, 23

sмiтн, D. E. (1969) Calif. Med., r10, 472

SMITH, H. E. (1944) U.S. Navy med. Bull., 42, 675

tAYlor, r. L., MAUrer, J. I., and tinklenberg, J. r. (1970) J. Amer. med. Ass., 213, 422

verhoeff, f. H., Bell, L., and walker, c. B. (1916) Proc. Amer. Acad. Arts Sci., 51, 627 